\title{
EVALUATING THE IMPACT OF THE CAPITATION GRANT AND THE SCHOOL FEEDING PROGRAMME ON ENROLL- MENT, ATTENDANCE AND RETENTION IN SCHOOLS: THE CASE OF WEWESO CIRCUIT
}

\author{
A. K. Osei-Fosu \\ Department of Economics, \\ Kwame Nkrumah University of Science and Technology, Kumasi, Ghana
}

\begin{abstract}
This study seeks to investigate the impact of the capitation grant and school feeding programme on school enrollment, attendance and retention in Ghana. The paper used difference-indifference method by comparing changes in enrollment, attendance and retention between before and after, and between beneficiary schools (treatment) and non-beneficiary schools (control). It also ran Ordinary Least Squares (OLS) regression to find the impact of the programmes on enrollment, attendance and retention for the 2001/2002 and 2008/2009 academic years. The study found from the regression results that the capitation grant had positive but not significant impact on enrollment. However, it can be said that the capitation grant caused an instantaneous increase in enrollment because it brought a one-time sharp increase and then settled. However, it did not have a significant impact on attendance and retention. It was also found out that the school feeding programme had positive and significant impact on school enrollment, attendance and retention. The study found out that the positive impact of the programmes was affected by the fees levied on school pupils by the Parent-Teacher-Association and the weather.
\end{abstract}

Keywords: Capitation Grant, School Feeding Programme, Enrollment, Attendance, Retention

\section{INTRODUCTION}

Education is widely considered to be critical for development. Many economists have emphasized the impact of education on economic growth (Lucas, 1988; Barro, 1991; Mankiw et al., 1992), although some others have raised questions about the causal relationship between education and economic growth. Education has also been found to play a crucial role in the adoption of new agricultural technologies in those countries (Foster and Rosenzweig, 1996). Finally, education is also seen as a means to improve health and reduce fertility (Schultz, 1997 and 2003; Strauss and Thomas, 1995) and is seen as an intrinsic good in itself (Sen, 1999). This general notion is emphatically expressed under the Millennium Development Goal aimed at achieving universal access to primary education by the year 2015, and eliminating gender disparity in education by 2015 .

Despite the tremendous progress in expanding enrollment and increasing years of schooling since 1960, over 100 million children of pri- 
mary school age are still not enrolled in school, with more than 70 percent living in Sub-Sahara Africa and South Asia (World Bank Independent Evaluation Group, 2002). In addition, the quality of schooling in developing countries is often very low. Grade repetition and leaving school at an early age are common, teachers are often absent from classrooms, and many children learn much less than the learning objectives set in the official curriculum (Lockheed and Verspoor, 1991; Harbison and Hanushek, 1992; Hanushek, 1995; Glewwe, 1999).

Over the years, successive governments in Ghana have instituted programmes and policies to make education, especially, basic education affordable and accessible to all people and to improve educational outcomes. For example, the first government introduced free education in the three Northern Regions. Other interventions included the supply of free textbooks, exercise books, pens and pencils to basic school pupils to reduce the financial burden on parents towards their children's education. Again, in the 1980s the government came out with educational reforms which introduced the Junior and Senior Secondary School concepts. The Reforms reduced the duration of basic education from ten to nine years and that of the secondary from seven to three years. The reforms also sought to give graduates employable skills as well as increasing their years of work. The Free Compulsory Universal Basic Education (FCUBE) was adopted in 1995 (Ghana National Education Campaign Coalition Report, 2007).

The educational situation in Ghana has improved over the years. Quantity and quality of schooling has improved. The trend in Primary Gross Enrollment since 1987 has been fairly flat until 2000. Since 2000 increasing percentage of Ghanaians of school-going age have attended school. For example, Gross Enrollment Ratio (GER) increased from $57 \%$ in $1999 / 2000$ to $86.5 \%$ in $2003 / 2004$ (UNICEF Report, 2007; Ahadzie, 2008). In spite of this, the country had not achieved total coverage of all school going age children. In a bid to fulfill its commitment to achieving the goal of the Free Compulsory Universal Basic Education (FCUBE) and its commitment to the United Nations goal of universal primary education by 2015 and the Millennium Development Goals on education, the government of Ghana introduced the capitation grant during the 2004/2005 academic year. The capitation grant covers the extra cost and levies (such as examination, facilities management, security charges, games and sports) that parents usually pay as "school fees" in public schools. It also introduced the National School Feeding Programme in the 2005/2006 academic year. Each pupil under the scheme was covered by a feeding grant of $\mathrm{GH} \phi$ 0.30 a day (Nsowah, 2008).

Osei et al. (2009) did a study on the effects of the capitation grant on education outcome in Ghana. The objective was to assess how the capitation grant has impacted on the Basic Education Certificate Examination (BECE) pass rates, gross enrollment ratios and gender difference in pass rates. The study used data from the Ghana Education Service for all 138 educational districts in Ghana between 2003 and 2007. Using regression analysis, the study found that; the capitation grant has not had significant impact on BECE pass rates in Ghana, no significant relationship existed between capitation grant and gross enrollment, and capitation grant has not impacted on bridging the gap between the BECE pass rates for male and female.

It is a general knowledge that to achieve improvement in performance in educational outcomes (for example pass rates in examination), there is the need, among other things, for attendance at schools and retention in classrooms. These facts give rise to the question as to whether the introduction of the Capitation Grant and School Feeding programme have led to an increase in basic school enrollment, improved attendance and sustained retention.

Many studies have been carried out to show the 
impact of various interventions on educational outcomes. For example, Schultz (2003) used randomized order of programme phase-in to examine the impact of the Progresa programme in Mexico, which provided cash grants to families conditional on their sending their children to school. He found an increase in enrollment of all students in grades 1 through 8, especially, among girls who had completed grade 6 . Vermeersch and Kremer (2005) examined the effect of school meals on school participation in Kenya and found that school participation went up in Kenyan preschools where a free breakfast was introduced than in comparison to schools where there were none. In many countries, parents face significant private costs of education, either for school fees or for other inputs such as uniforms. In Kremer et al. (2002), Moulin, Namunyu, and Kremer evaluated a programme in which an NGO, International Christelijk Steunfonds Africa (ICS), provided uniforms, textbooks, and class-room construction to seven schools, randomly selected from a pool of poorly performing candidate schools in Kenya. They found that school dropout rates fell considerably in treatment schools, and after five years pupils in treatment schools had completed about 15 percent more schooling.

It is against this background that this current paper seeks to investigate the impact of the capitation grant and school feeding programmes on school enrollment, attendance and retention in some schools in the Weweso Circuit of the Kumasi Metropolitan Area in the Ashanti region of Ghana. It is the hope that the results of this paper will be a good guide to educational policy makers to know the direction they should go with respect to these two programmes in Ghana.

\section{MATERIALS AND METHODS}

\section{Data Type, Source and Sampling}

The study randomly selected 20 primary schools from the Weweso circuit of the Asokwa Sub-Metro education district in the Kumasi Metropolitan Area in the Ashanti region of Ghana. Weweso circuit was chosen for its special advantageous characteristics. It is firstly typical of any educational circuit but it's proximity to Kumasi Metropolis does not make it suffer from the usual lack of teaching staff, which are typical phenomenon in the remote areas, that could affect the educational outcomes. The author obtained the list of all basic schools in the circuit that were beneficiaries and non-beneficiaries of the school feeding programme and randomly selected 20 of them (10 of them were under the school feeding programme, while 10 were not). However, all the schools were beneficiaries of the capitation grant. The study covered the period from the 2001/2002 academic year to the 2008/2009 academic year.

Outcome data of the study included gross enrollment, attendance and retention. The covariate variables were capitation grant, school feeding, seasonal effects and Parent Teacher Association approved fees. Gross enrollement was defined as the total number of pupils in the schools at the beginning of the academic year. This was derived from the total number of pupils in the registers of each class summed up.

Attendance was recorded as present at school and was taken to mean the pupil reported at school and was marked at the beginning of classes and stayed till the end of class. It was also taken from the class registers of each class. Pupils who reported in the morning and were marked present but did not stay till the end of the school period were recorded absent. This category was indicated in the registers with a present sign in a circle. The attendance was taken per each term, giving three sets for each class in a year. Basic schools do an average of 13 weeks per term and an average of 5 days in a week with no public holidays. A pupil is therefore expected to achieve maximum attendance of 65 days, which was adjusted to 63 days since each term begins on Tuesdays and vacates on Thursdays and therefore each pupil loses 2 days in a term. Retention was also defined as the number of pupils who stayed in school up to the end of the academic year. This 
was simply measured by subtracting the number of pupils at the end of the academic year in the school from the total enrollment at the beginning of the academic year. This was also taken from the registers of the sampled schools. Capitation grant was represented by a dummy with year without capitation scored 0 and the years with capitation grant implementation scored 1. Similarly, school feeding programme was also represented by a dummy; 1 for years with or school with school feeding, otherwise it was 0 . Season was also represented by a dummy; 1 for raining and 0 for dry season.

In Ghana raining season has negative impact on school attendance due to distance some pupils commute to school on foot. This variable was recorded from the weather chart of the region where these schools are located. Approved Parent-Teacher-Association (PTA) fees was measured in $\mathrm{GH} \phi$ and was derived from the school's records. Approved Parent-Teacher-Association (PTA) fees put financial burden on parents and this could deter poor parents from sending their children to school.

The method of analysis was basically, difference-in-difference. Capitation grant benefits every pupil enrolled in public schools. Hence, the study compared the effects of the programme with respect to enrollment between periods before and after. The study intended to compare public schools benefiting from the grant with private schools but it came out that the private schools turn to have some fixed level of enrollment which they do not change.

Again, attendance and retention in the private schools turn to be almost $100 \%$ throughout and so there was no basis for comparison. In the case of the school feeding programme, the study compared changes in enrollment, attendance and retention between before and after, and between beneficiary schools (treatment) and non-beneficiary schools (control). Ordinary Least Squares regression was run to find the impact of the programmes on enrollment, attendance and retention over the period of study.

\section{Empirical Model}

The paper is based on the assumption that capitation grant has positive impact on school enrollment, attendance and retention. The explanation is that the grant is expected to remove the financial barrier created by levies hitherto imposed on parents and guardians which deterred those who could not afford to pay from sending their wards to school. One of the reasons some children in Ghana did not attend school was that their parents simply could not afford to pay the levies charged by the schools.

Despite the policy of free tuition in basic schools, many schools charge levies as a means of raising funds, for example, for school repairs, extra classes, and motivation for teachers. This had the effect of deterring many families, particularly the poorest, from sending their children to school. The school feeding programme is also assumed to cause increase in gross enrollment, improve class attendance and retain pupils in schools. The idea was that it would release the financial burden on parents, reduce hunger among children and increase school enrollment. It would also entice pupils to stay in school by reducing truancy and improving retention, as well as attendance. Based on these hypotheses, the study postulates the following Ordinary Least Squares regressions;

Enrol $_{i t}=\alpha+\beta_{1} \mathrm{Cap}_{i t}+\beta_{2} \mathrm{Sfp}_{i t}+\beta_{3} \mathrm{Pta}_{i t}+\beta_{4} \mathrm{Sea}_{t}+\mathcal{\varepsilon}$ (1) where Enrol = enrollment, $C a p=$ capitation grant, $S f p=$ school feeding programme, $P t a=$ Parent-Teacher-Association approved fees, Sea = season, $\varepsilon=$ error term, $\mathrm{i}=1,2,3, \ldots \mathrm{N}$ schools, and $\mathrm{t}=1,2,3, \ldots$ T years.

Attend $_{i t}=\phi+\gamma_{1}$ Cap $_{i t}+\gamma_{2}$ Sfp $_{i t}+\gamma_{3}$ Pta $_{i t}+\gamma_{4}$ Sea $_{t}+\mu$

where, Attend $=$ Attendance; $\tilde{a}=$ error term

$R_{e t} t_{i t}=\varphi+\delta_{1} C a p_{i t}+\delta_{2} S f p_{i t}+\delta_{3} P t a_{i t}+\delta_{4} S e a_{i}+\omega$

Where Ret is Retention and $\ddot{i}$ is error term

\section{RESULTS AND DISCUSSION}

Table 1 shows the summary results of the variables for the period under consideration. Column 1 shows the variables whilst columns 2,3 , 
4 and 5 show the means, standard deviation, baseline mean values of the variables, and mean values at the end of the study period, respectively, for the treatment group. Columns 6 , 7,8 and 9 also show the values of the same variables for the control group.

From Table 1 the mean enrollment at the 2001/2002 academic year was 163 and 165 pupils for the treatment and control group respectively. This rose to 361 and 365 pupils, with a period mean of 245 and 243 pupils for the treatment and control group respectively. The test statistic conducted using students' ' $t$ ' test of significance at $5 \%$ error level on the data between the treatment and control groups, and between enrollment before and after the institution of the capitation grant shows that there is no significant difference in enrollment trends between the treatment and control groups. However, there was a significant difference between enrollment before the institution of the capitation grant in 2001/2002 academic year and 2008/2009 academic year.

From Table 1 the mean attendance for the treatment group was 16,554 days in 2001/2002 academic year, with a mean attendance per person per term of 34 out of 63 days. This went up to 44,856 days with 41 mean attendance per person per term out of 63 days. In the case of the control group the mean attendance at 2001/2002 academic year was 16,561 days with 33 days mean attendance per person per term out of 63 days. It increased to 40,375 days with 37 days mean attendance per person per term out of 63 days. The data indicates that mean attendance were almost the same (16,554 and 16,561 days) for both groups before the programmes but different in the 2008/2009 academic year (44,856 and 40,375 days). There was also significant difference in attendance for both the control and the treatment groups prior to and after the programmes (16,554 and 44,856 days for the treatment groups, and 16,561 and 40,375 days for the control group). However, the difference between before and after the programmes was higher for the treatment group (28,302 days as against 23,814 days for the treatment group and control group respectively).

It is also clear from Table 1 that the mean retention at the 2001/2002 academic year was 158 and 161 for the treatment and control groups respectively. This rose to 345 and 306 , with period means of 243 and 241 for the treatment and control groups respectively. The data portray that there was no significant difference in retention between the treatment and control groups before the programmes (the difference between the two groups was only 3 pupils). However, there is a significant difference in retention between the treatment and control groups at 2008/2009 academic year (31 pupils). Obviously, there is difference in retention prior to and after the programmes for both the treatment group and the control group, but it was greater in the case of the treatment group than the control group (187 and 145 for the treatment group and the control group, respectively).

Table 1: Summary results of variables $(2001 / 2002-2008 / 2009$ academic year)

\begin{tabular}{|c|c|c|c|c|c|c|c|c|}
\hline \multirow[t]{2}{*}{ Variables } & \multicolumn{4}{|c|}{ Treatment Group } & \multicolumn{4}{|c|}{ Control Group } \\
\hline & Mean & Std Dev & 2001/02 & 2008/09 & Mean & Std Dev & 2001/02 & 2008/09 \\
\hline $\begin{array}{l}\text { Enroll- } \\
\text { ment }\end{array}$ & 245 & 3.5195 & 163 & 361 & 243 & 3.6328 & 165 & 365 \\
\hline $\begin{array}{l}\text { Atten- } \\
\text { dance }\end{array}$ & 21,705 & 4.6592 & 16,554 & 44,856 & 18,689 & 4.5320 & 16,561 & 40,375 \\
\hline Retention & 243 & 3.6715 & 158 & 345 & 241 & 3.5071 & 161 & 306 \\
\hline PTA Fees & 1.53 & 2.0739 & 0.35 & 3.50 & 1.53 & 2.1956 & 0.35 & 3.50 \\
\hline
\end{tabular}

Source: Field survey, 2009 
Table 2 shows the regression results of the programmes on enrollment. Column 2 shows results of enrollment as a function of capitation grant and Parent-Teacher-Association fees as interactive variable. Column 3 shows results on enrollment as a function of School Feeding Programme and Parent-Teacher-Association fees. Finally, column 4 shows the results of enrollment as a function of all the three variables.

From the results capitation grant is positively related to enrollment but not statistically significant. It implies that capitation grant does not significantly influence enrollment. This goes to confirm the results of earlier study by Osei et al. (2009). The possible explanation is that the capitation grant led to a one time high quantum jump in enrollment and there after it stabilized. From Figure 1 the mean percentage change in enrollment in 2004/2005 academic year, before capitation grant was instituted, averaged 1.12 but the very year the grant was instituted (2005/2006 academic year) the mean percentage change increased to 1.17 . In $2006 / 2007$ academic year it shot up to an average of 17.36. It then dropped to 1.11 and to 0.11 in 2007/2008 and 2008/2009 academic years, respectively. This means that in terms of trend core mean percentage changes have been maintained but at higher enrollment.
From Table 2 School Feeding Programme was found to be positively related to enrollment and it was statistically significant at less than $10 \%$ error level. It shows that School Feeding Programme caused enrollment to increase significantly for those who benefit (0.0396), meaning that a $100 \%$ increase in School Feeding Programme will increase enrollment by about $4 \%$ point.

The coefficient of Parent-Teacher-Association fees (-0.2638) from Table 2 however shows that Parent-Teacher-Association fees have negative impact on enrollment. This implies that schools that imposed high Parent-TeacherAssociation fees experienced reduced enrollment as parents found it difficult to pay. This was the reason why the capitation grant was instituted.

Table 3 depicts the regression results of the impact of the programmes on attendance. Column 2 is the results with capitation grant as independent variable. Column 3 show results of attendance with School Feeding Programme as independent variable, and column 4 shows the results of attendance as a function of all the three variables. In all cases Parent-TeacherAssociation fees and Raining Season were used as interactive variables.

Table 2: Regression results of impact of the programmes on enrollment

\begin{tabular}{lccc}
\hline Dependent Variable & $\mathbf{( 1 )}$ & Enrollment & (3) \\
\hline Capitation Grant & 0.0294 & $\mathbf{( 2 )}$ & 0.1063 \\
& $(0.39180)$ & & $(0.2849)$ \\
School Feeding Programme & & & $0.0724^{*}$ \\
& & $0.0396^{*}$ & $(0.5276)$ \\
Parent-Teacher-Association Fees & $-0.2074^{* *}$ & $(0.4729)$ & $-0.2638^{* *}$ \\
& $(2.0814)$ & $-0.2603 * *$ & $(2.0385)$ \\
Constant & 12.5927 & 8.4528 & 15.0538 \\
& $(8.2630)$ & $(8.3853)$ & $(6.9385)$ \\
\hline
\end{tabular}

Note: Figures in parenthesis are standard errors and * and ** indicate significance at less than $10 \%$ and $5 \%$, respectively. 
Evaluating the impact of the capitation grant...

61

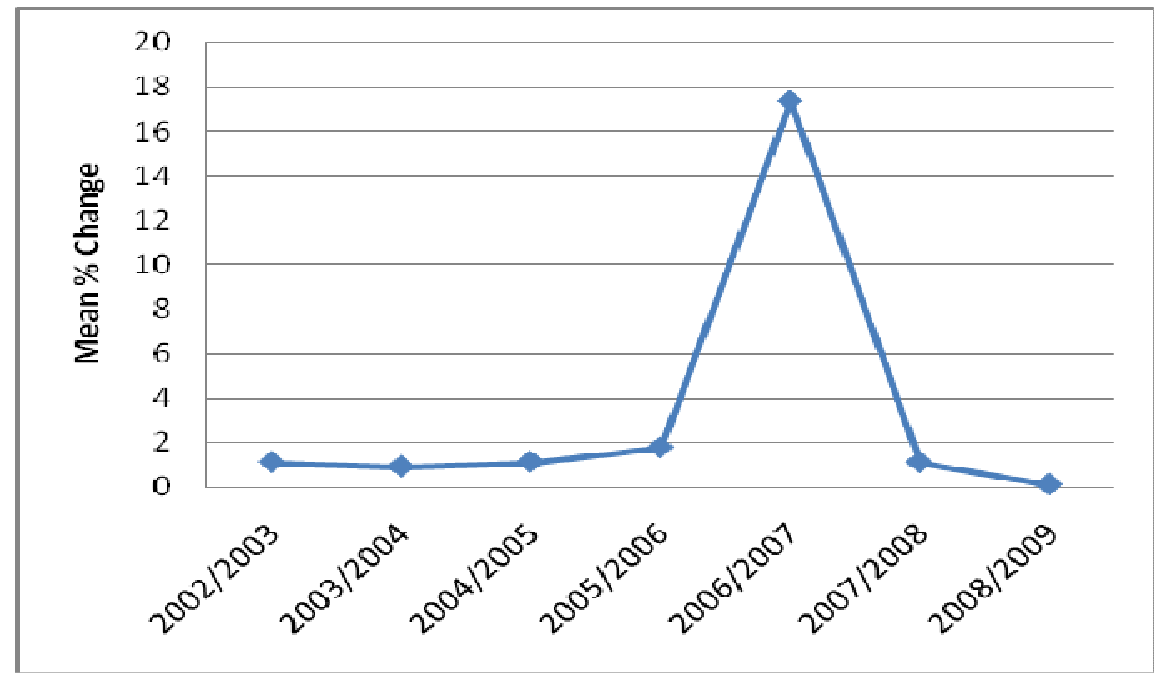

Figure 1: Mean Percentage Change in Enrollment

Table 3: Regression results of impact of the programmes on attendance

\begin{tabular}{lccc}
\hline Dependent Variable & $\mathbf{( 1 )}$ & Attendance & $\mathbf{( 3 )}$ \\
\hline Capitation Grant & 0.0235 & $\mathbf{( 2 )}$ & 0.0328 \\
& $(0.3401)$ & & $(0.3081)$ \\
School Feeding Programme & & & $0.9837 * * *$ \\
& & $0.9472 * * *$ & $(0.3650)$ \\
Parent-Teacher-Association Fees & $-0.0036^{*}$ & $(0.39672)$ & $-0.0110^{*}$ \\
& $(0.8294)$ & $-0.0104 *$ & $(0.7081)$ \\
Raining Season & $-0.8327 * *$ & $-0.7482)$ & $-0.8701 * *$ \\
& $(0.4197)$ & $(0.3892)$ & $(0.3182)$ \\
Constant & 18.0934 & 13.2740 & 12.9476 \\
& $(10.6270)$ & $(8.1633)$ & $(8.0093)$ \\
\hline
\end{tabular}

Note: Figures in parenthesis are standard errors and *,**and *** indicate significance at less than $10 \%, 5 \%$ and $1 \%$, respectively.

The results indicate that capitation grant had a small positive relationship with attendance and not statistically significant. A $100 \%$ increase in the capitation grant will increase attendance by only $3.3 \%$. On the other hand School Feeding Programme has very high positive impact on attendance. The results show that $100 \%$ increase in School Feeding Programme will in- 
crease attendance by about $98 \%$. School Feeding Programme is found to be statistically significant at less than $1 \%$ error level. Here also, Parent-Teacher-Association fees were found to impact negatively on attendance, though small yet statistically significant at less than $10 \%$ error level. It was explained that school authorities punish pupils who refuse to pay the fee at the right time and hence defaulting pupils are deterred and absent themselves. Finally, the impact of the raining season on attendance was found to be negative and statistically significant. It came out that those terms that coincided with the raining season had more absenteeism.

Table 4 shows the regression results of the impact of the capitation grant and the school feeding programme on retention. The results show that capitation grant has a small positive impact on retention and not statistically significant. A $100 \%$ increase in the capitation grant will only increase retention by $4.2 \%$. The results however show a positive significant relationship between school feeding programme and retention. A $100 \%$ increase in School Feeding Programme will increase retention by about $99 \%$. This implies that pupils are enticed to stay in school by the School Feeding Programme. Contrary, Parent-Teacher-Association fees were found to impact negatively on retention and statistically significant at less than $10 \%$ error level.

\section{CONCLUSION}

This study sought to investigate the impact of the capitation grant and school feeding programme on school enrollment, attendance and retention in some schools in Ghana. The paper used difference-in-difference by comparing changes in enrollment, attendance and retention between, before and after, and between beneficiary schools (treatment) and non-beneficiary schools (control). It also ran OLS regression to find the impact of the programmes on enrollment, attendance and retention for the period 2001/2002 and 2008/2009 academic years. The study found that from the regression results capitation grant had a positive but not significant impact on enrollment. However, it can be said that it caused an instantaneous increase in enrollment because it brought a one-time sharp increase and then it settled. Hence, the paper can conclude that the capitation grant has had an impact on enrollment. On the other hand the capitation grant was found not to have significant impact on attendance and retention. It also came out that the school feeding programme had high positive and significant impact on school enrollment, attendance and retention. The study found that the positive impact of the programmes was affected by the fees levied on school pupils by the Parent-TeacherAssociation. Also, the paper found that school attendance was significantly impacted by the raining season.

Table 4: Regression results of impact of the programmes on retention

\begin{tabular}{lccc}
\hline Dependent variable & \multicolumn{2}{c}{ Retention } & $(\mathbf{3})$ \\
\hline Capitation Grant & $(\mathbf{1})$ & $\mathbf{( 2 )}$ & 0.0420 \\
& $(0.0305$ & & $(0.0286)$ \\
School Feeding Programme & & $0.9273^{* * *}$ & $0.9918^{* * *}$ \\
& & $(0.2845)$ & $(0.2561)$ \\
Parent-Teacher-Association Fees & $-0.0629^{*}$ & $-0.0295^{*}$ & $-0.0256^{*}$ \\
& $(2.0938)$ & $(2.0183)$ & $(1.9744)$ \\
Constant & 10.8267 & 7.0255 & 6.8695 \\
& $(13.0852)$ & $(12.4581)$ & $(9.2845)$ \\
\hline
\end{tabular}

Note: Figures in parenthesis are standard errors and * and *** indicate significance at less than $10 \%$ and $1 \%$, respectively. 


\section{REFERENCES}

Ahadzie, W. (2008). "Global March Against Child Labour/ICCLE's Assessment of Fast Track Initiative in Ghana", A Report on Ghana's Progress towards Achieving the EFA Goal, June, 2008, www.iccle.org/ images/ghana.pdf, accessed on April 5, 2010 .

Barro, R. (1991). "Economic Growth in a Cross -Section of Countries," Quarterly Journal of Economics, 106(2): 407-443.

Foster, A. D. and Rosenzweig, M. R. (1996). "Technical Change and Human-Capital Returns and Investments: Evidence from the Green Revolution", The American Economic Review, 86 (4):931-953.

Ghana National Education Campaign Coalition Report- $4^{\text {th }}$ edition, August 2007 Glewwe, P. (1999). The Economics of School Quality Investments in Developing Countries, Saint Martin's Press, New York.

Hanushek, E. A. (1995). "Interpreting Recent Research on Schooling in Developing Countries", World Bank Research Observer, 10:227-246.

Harbison, R. and Hanushek, E. (1992). Educational Performance of the Poor: Lessons from Rural Northeast Brazil, Oxford University Press, Oxford.

Kremer, M., Moulin, S. and Namunyu, R. (2002). Unbalanced Decentralization, Mimeo, Harvard University .

Lockheed, M. and Verspoor, A. (1991). "Improving Primary Education in Developing Countries", Oxford University Press, New York.

Lucas, R. (1988). "On the Mechanics of Eco nomic Development," Journal of Monetary Economics, 22: 3-42.
Mankiw, N., Romer, G. D. and Weil, D. (1992). "A Contribution to the Empirics of Economic Growth," Quarterly Journal of Economics, 107(2): 407- 437.

Nsowah, M. (2008). "School Feeding Pro gramme: Cooked up to Fail?", www.modernghana.com, accessed on April 5, 2010.

Osei, R. D., Owusu, G. A., Asem, F. E. and Kotey, R. L. (2009). "Effects of Capitation Grant on Education Outcomes in Ghana", ISSER, Global Development Network, www.gdnet.org, accessed on April 5, 2010.

Schultz, T. P. (2003). "School Subsidies for the Poor: Evaluating the Mexican Progresa Poverty Program", Journal of Development Economics, 74 (1), 199-250.

Schultz, T. P. (1997). "Demand for Children in Low Income Countries," in Rosenzweig, M. And Stark, O. (eds), Handbook of Population and Family Economics, Elsevier Science B. V., North Holland.

Sen, A. (1999). Development as Freedom, Knopf, New York.

Strauss, J. and Thomas, D. (1995). "Human Resources: Empirical Modeling of House hold and Family Decisions" in Behrman, J. and Srinivasan, T. N. (eds), Handbook of Development Economics, Vol 3, Elsevier Science B. V., North Holland.

UNICEF (2007). "Achieving Universal Primary Education in Ghana by 2015: A Reality or Dream?", Division of Policy and Planning Working Papers, June, 2007, www.unicef.org/policyanalysis, accessed on April 5, 2010.

Vermeersch, C. and Kremer, M. (2005). "School Meals, Educational Attainment, and School Competition: Evidence from a 


\section{Osei-Fosu}

Randomized Evaluation", World Bank Policy Research Working Paper, WPS3523.

World Bank Independent Evaluation Group (2002). "Universal Primary Education:

Evaluation Highlights", www.worldbank.org/oed/education/ documents/primary_ed_chap1.pdf, accessed on May 10, 2010. 